\title{
Differentiated instruction in the mathematics classroom: Teachers' teaching experience in a teacher professional development
}

\author{
Fina Hanifa Hidayati*
}

Universitas Islam Negeri Sunan Kalijaga, Jalan Marsda Adisucipto Yogyakarta, Indonesia

\begin{tabular}{lr}
\hline A R T I C L E I N F O \\
Original Article \\
DOI: 10.18860/ijtlm.v3i1.9699 \\
\hline Keywords: \\
$\begin{array}{lr}\text { Differentiated } & \text { Instruction, } \\
\text { Mathematics } & \text { Classroom, } \\
\text { Teacher } & \text { Professional } \\
\text { Development } & \end{array}$
\end{tabular}

\begin{abstract}
A B S T R A C T
Differentiated instruction is an approach that can be used to facilitate students with various characteristics and help them to master mathematics in every topic learned. This study describes teachers' performance in implementing differentiated instruction. In the second secondary school level, thirty mathematics teachers designed mathematics lessons using differentiated instruction in different topics, peer-reviewed, and peer-presented. Implementing the lesson in a real classroom was done while conducting classroom observation to see what works well during the learning process and improve it. Qualitative descriptive method was used to describe the process of research and analyze findings during the lesson through observation and forum group interview. From this process, teachers prepared instruction based on students' abilities, took into account personal mathematics understanding, and helped students achieve mathematics learning goals. Teachers also learned strategies for helping students learned. Meanwhile, students enjoyed the learning process through their different ways of learning.
\end{abstract}

(C) 2020 IJTLM.

This is an open-access article distributed under the CC-BY-SA license.

*Corresponding author.

E-mail: fina.hidayati@uin-suka.ac.id

How to cite: Hidayati, F. H. (2020). Differentiated instruction in the mathematics classroom: Teachers' teaching experience in a teacher professional development. International Journal on Teaching and Learning Mathematics, 3(1), 37-45.

\section{INTRODUCTION}

Different students' progress in mastering some topics in the classroom often happens. It also occurred in the mathematics classroom because the teachers use the same method for all students' type. On the other side, it can be sure that one size teaching instruction can't be fit for all kinds of students (Bondie, Dahnke, \& Zusho, 2019; Borja, Soto, \& Sanchez, 2015; Magableh \& Abdullah, 2020). Today, students with different needs have to stay in the same classroom to gain the same goals in the learning process (Fountas \& Pinnell, 2018; Morgan, 2014). To accommodating students' differences, it would be better to facilitate students in different paths appropriate with the type of students to achieve learning goals by applying differentiated instruction.

Differentiated instruction talks about how different preparing instruction among students, see the way students learn based on their preference and personal interest (Algozzine \& Anderson, 2007). Differentiation instruction is related to addressing students' different phases of learning (Pozas, Letzel, \& Schneider, 2020; Sharp, Jarvis, \& McMillan, 2020). That did improve students' capability from novice to capable and to proficient. It is worth enhancing the students' progress by implement differentiated instruction in the mathematics classroom (Borja et al., 
2015; Hackenberg, Creager, \& Eker, 2020). By doing this strategy to the learning process, that students achieve mathematics learning goals by their own-paths. Differentiated instruction provides a classroom where students may take different paths to content acquisition, to grasping ideas process, and to develop products. Differentiated instruction can be used to accommodate students' differences (Tomlinson \& Moon, 2013). Tomlinson, Moon, and Imbeau (2015) revealed that teachers can differentiate the instruction through content, process, product, and affect/environment according to the students' readiness, interest, and learning profile. Differentiating the instruction trough content can be executed by giving different topics/subtopics to learn by students to achieve the learning goals. Teachers also can be differentiating through the process by preparing various students' activities to learn. Demonstrate the learning by developing different products is key to differentiating the instruction through the product. In contrast, in differentiating instruction through affect/environment, teachers should set-up/adjust the classroom setting. Various strategies can be used to implement instruction, namely small-group instruction, tiered assignment, and independent project.

In the 21st century, fundamental mathematics concepts are needed by students to understand. Their ability to translate problems in daily life into a form of relevance mathematics is needed in this era. This situation is relevant to the development of teachers' skills in preparing students in the 21 st century. Teachers need to constantly improve their professional knowledge to be highlevel knowledge teachers as part of teachers' professional development (Schleicher, 2012). Teachers' professional development is about how teachers as facilitators, learn and use their knowledge to help their students learn (Postholm, 2012). In line with Postholm (2012), Avalos (2011) explained that teachers' professional development is about how teachers learn and transforming knowledge in the classroom and give benefits to students' growth. Professional development is widely accepted to improve learning (Kennedy, 2016). It needs a lot of experience and train time by time to become a professional teacher and achieve a successful learning process. There are many things to do to gain a professional teacher, one of which is preparing a strategy/method in the learning process. Differentiated instruction may include one the choice to help teachers in developing their professional skills. By preparing and implementing differentiated instruction, teachers learn how to facilitate various students' characteristics in understanding mathematics subjects better.

Many teachers might already implement strategies to address students' diversity, but their understanding far from differentiated instruction (Melesse, 2016). The term seems new for them rather than another approach, namely scientific learning method, lesson study in the mathematics classroom. There are some differentiated instruction courses provided for teachers, but still, it is needed for them to have more information on differentiated instruction strategies (Njagi, 2014).

Recent studies described the effectiveness of applying differentiated instruction in the mathematics classroom. Awofala and Lawani (2020) reported that students' mathematics achievement increase through differentiated instruction. Students were more motivated and involved during differentiated instruction (Hapsari, Darhim, \& Dahlan, 2018). Teachers' professional development about differentiated instruction in the mathematics classroom had a positive effect on students' achievement (Prast, Van de Weijer-Bergsma, Kroesbergen, \& Van Luit, 2018). Ismajli and Imami-Morina (2018) showed that differentiated instruction is succeed implemented by teachers in applying interactive strategies to meet of all the Studeothereeds. Those studies give insight for other teachers to implement differentiated instruction in 
mathematics classrooms, but need another insight of practical ways in the implementation of this approach. According to this problem, this study wants to dig deeper practical implementation of differentiated instruction and see the teachers' performance in the senior secondary school mathematics classroom in implementing differentiated instruction from the preparation until the implementation in the real mathematics classroom. Further, teachers can prepare the future mathematics lesson better to accommodate every students' needs based on their experience in implementing differentiated instruction. Therefore, the research problems of this study are: how does the practical implementation of differentiated instruction and the teachers' performance in the senior secondary school mathematics classroom in implementing differentiated instruction?

\section{METHOD}

This study aims to describe the practical implementation of differentiated instruction and teachers' performance in the senior secondary school mathematics classroom in implementing differentiated instruction from the preparation until the implementation in the real mathematics classroom. Purposive sampling is used as a sampling technique in which prospective subjects were selected with the highest motivation to involve in this study.

The process of differentiated instruction was prepared by 30 senior secondary school mathematics teachers, which are divided into six groups. They designed and peer-reviewed six different lesson plans, followed by peer teaching. To design the lesson plan, teachers take into account students' characteristics in the classroom. They identify students' mathematics achievement and learning style to design the lesson. Students' mathematics achievement is taken from students' mathematics achievement during the last semester while identifying learning style, and teachers gave a learning style test. Peer Teaching was also conducted to improve the learning process before having real teaching in the mathematics classroom in a school at Yogyakarta, Indonesia.

A qualitative descriptive method was used in this study. Observation and forum group interview was done to gather the data. The observation was done in every process of differentiated instruction to record findings. Forum group interviewed were conducted to dig information during the process of differentiated instruction. The data from observation and forum group interviewed were doubly checked and filtered based on the focus of this study, then described to explain the teachers' performance in the senior secondary mathematics classroom in implementing differentiated instruction.

\section{RESULTS AND DISCUSSION}

\subsection{Pre Lesson Planning}

Before planning the lesson, teachers identify students' characteristics based on students' mathematics achievement during the last semester. Then, they divided them into three categories names, slow, medium, and fast learner, and determined based on Table 1. Some groups only divided students into two parts, slow and fast learner. Students' scores with Minimum Exhautiveess Criteria, i.e., 70 or more, are categorized to become fast learners. Those who have scored less than 70 become slow learners.

Table 1. Learners' score criteria

\begin{tabular}{cc}
\hline Fast & $\overline{\bar{X}}+0.5 S D<$ score \\
Medium & $\bar{X}-0.5 s \leq$ score $\leq \bar{X}+0.5 S D$ \\
Slow & score $<\bar{X}-0.5 S D$ \\
\hline
\end{tabular}


Teachers also analyze students' learning styles to decide the best teaching method in mathematics classrooms based on the test they participated in before. Some groups might not take into account the difference in learning style and focus on the majority of the learning style to design the lesson. Most of them dig deeper into the learning method based on the learner categorization then design worksheets based on it. The worksheet in Figure 1 is used as a tool to help students in mastering the mathematics concepts and facilitate the different learners to reach the same goals of the materials.

There are two main aspects to be considered in implementing differentiating instruction in the mathematics classroom, first, relevant aspects that characterize students' needs, and second, elements that can be differentiated. To plan the instruction, teachers may consider students' characteristics names are readiness, interest, and learning profile. Readiness reflects what a student currently knows, understands, and can do in light of what the teacher is planning to teach next. The interest provides great motivation for students. It takes great attention to what a student thinking about, enjoys learning about, and doing. The learning profile explains which a typical student learns. Further, learning style, intelligence preference, gender, and culture are very closely related to every students' learning profile (Tomlinson \& Moon, 2013). To design differentiated instruction, teachers may focus on one thing, students' readiness, interest, or learning profile. It can help to enhance the quality of learning and developing lesson scenarios (Scigliano \& Hipsky, 2010). Therefore, those groups decided to focus on the students' readiness (based on students' ability) is the best choice to avoid a messy mathematics lesson. Further, teachers design learning activity in the lesson plan and doing the validation process with experts. Once the ideal lesson plan is met, peer teaching sessions will be done.

\subsection{Lesson Planning}

Lesson plans designed by the teachers got some inputs from experts to become an ideal lesson plan. It was such a good discussion among them to prepare the best lesson for different students' characteristics. There are some ways to design differentiated instruction for students. First, for instance, provide different types of the worksheet to master one topic.

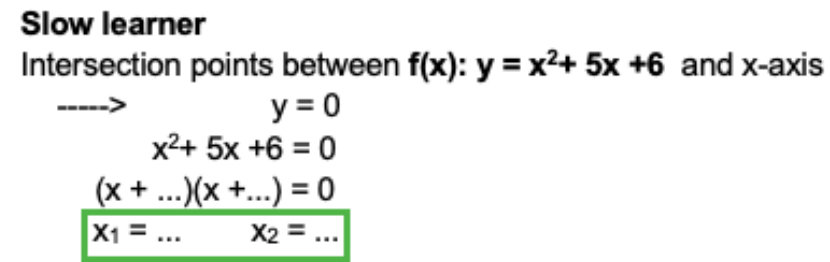

* So, intersection points between curve and $\mathrm{x}$-axis are $\mathrm{A}(\ldots, 0)$ and $\mathrm{B}(\ldots, 0)$

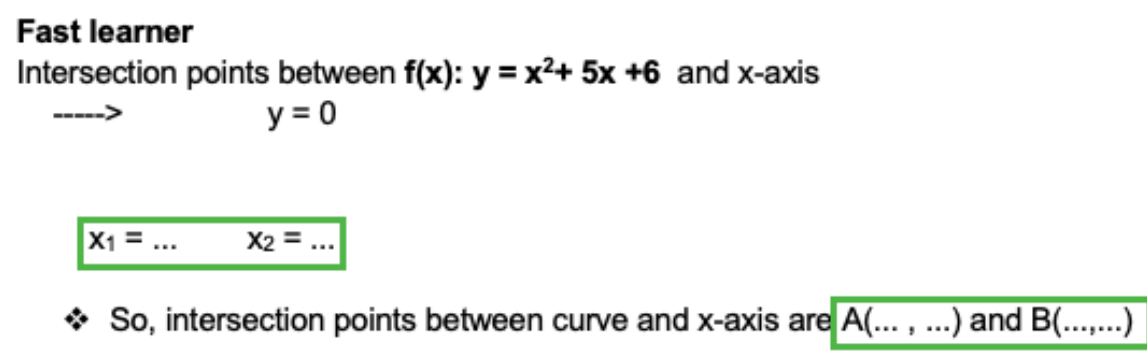

Figure 1. Worksheet for a slow and fast learner 
Figure 1 showed how the teacher provides a worksheet for slow learner and fast learner in case of finding intersections points between curve $f(x)=a x^{2}+b x+c$ and the $x$-axis. The teacher provides some hints for slow learners and no hints for fast learners to find the intersection point between the curve and $x$-axis. It is because slow learner seems to have less understanding in dealing with factorization.

Second, when students want to learn about the effect of the parabola graph $f(x)=a x^{2}+$ $b x+c$ when changing any constant $a, b$, and $c$, teachers may give different tasks for students based on their level of difficulty. The slow learner was given a task to observe the effect of the parabola graph when the value of $a$ was changed. While fast learner had to observe what would happen if the value of $b$ and $c$ was changed. Since all of the students have to master the effect of changing any constant $a, b$, and $c$ to the parabola graph $f(x)=a x^{2}+b x+c$, then strategy used by the teachers was made heterogeneous group consist of slow learner who observe first about the effect of the parabola graph when the value of $a$ was changed and fast learner who observe first about the effect of the parabola graph when the value of $b$ and $c$ was changed. They share the strategy used before so that in every group understand the concept of the parabola graph $f(x)=a x^{2}+b x+c$ effect when changing any constant $a, b$, and $c$. In this situation, the objective of the lesson can be reached by all of the students using differentiated instruction based on students' abilities. For every group discussion, teachers also keep attention to the way students discuss and solve the problem. Teachers need to carefully facilitate students; they should consider to whom they help and who is no need (Sternberg \& Zhang, 2005). The role of the teacher in this view is paramount (Watts-Taffe et al., 2012).

\subsection{Peer Teaching}

Observation during peer teaching sessions is an important session to have some inputs during the lesson and improve the lesson plan to prepare the real lesson implementation in the classroom. Although they planned the lesson carefully, still, during peer teaching, they found some things to be improved, for instance, steps in the worksheet or scenario in delivering the topics. This process helps them so much to face the real students in the real classroom.

Some suggestion is given after the peer teaching process:

Observer 1:teacher should manage well when grouping students in the classroom, either the way to inform the group to students or place/chairs setting for every group to work.

Observer 2: it's better to have clear instruction for every activity to avoid students' confusion

Observer 3: avoid too long facilitating certain groups in the learning process. The teacher should give the same proportion of time for every group.

\subsection{Real Teaching}

Real teaching in mathematics Classroom was done to implement the lesson plan of Differentiated Instruction. Figure 2 shows the teacher teaches in the classroom, while Figure 3 shows students worked in groups when solving problems given by the teachers. 


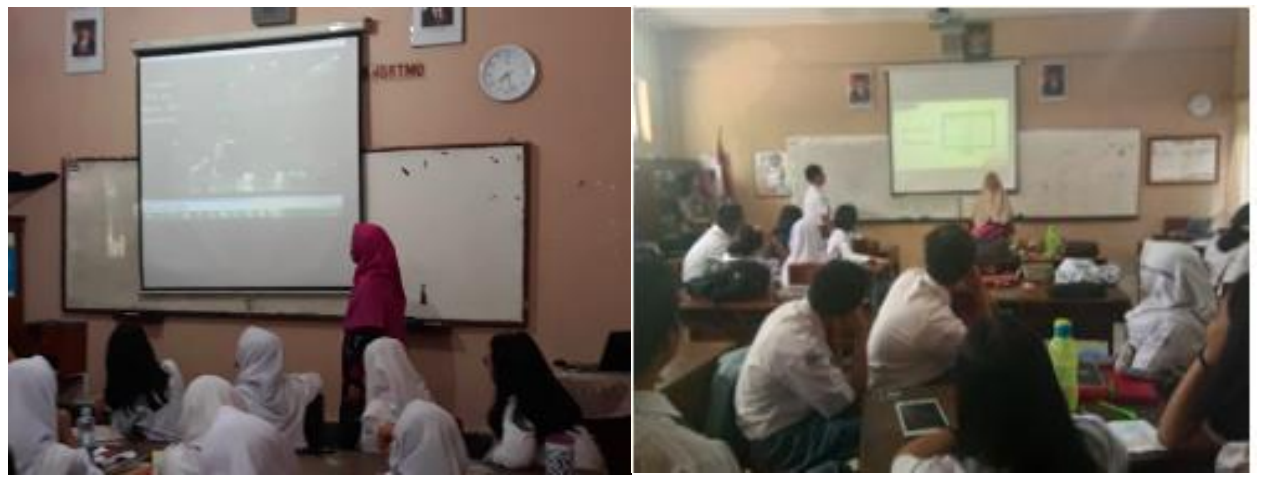

Figure 2. Teachers implemented real teaching of differentiated instruction

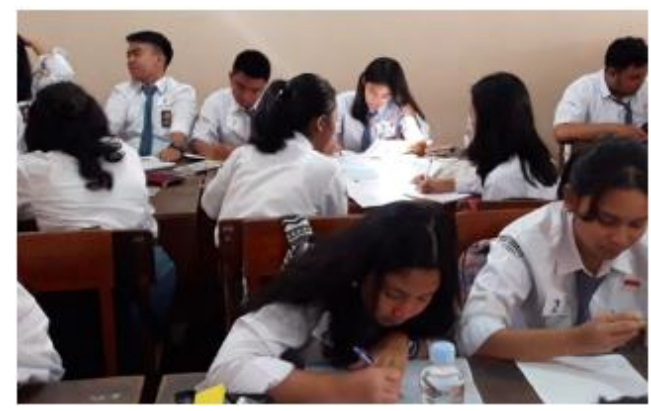

Figure 3. Students worked in group

The real implementation of the lesson is not always perfect though they have done the peer teaching before. It is always something new that happens in the classroom and gives good feedback to improve the next lesson. During the implementation process, teachers will see what works well and what kind of things need to be improved during the lesson, especially in facilitating different students' needs. Reflection after the lesson (peer/real teaching) is a must, again to gain better lesson (Parsons, Dodman, \& Burrowbridge, 2013). During the implementation process, it was shown that teachers took note of the important things that happened in the classroom.

At the end of the learning process, some students were appointed to share the discussion in front of the class to ensure all students got the right concept and achieve the goals. This is the best moment for teachers to emphasize the important concept to all of the students. This kind of activity made students enjoy the learning process since they find the concept by themselves and group discussion, which gives more support for them to learn well. This is consistent with (Goddard, Goddard, \& Kim, 2015) that by providing the differentiated instruction, students are motivated in the learning process, and soon, it will improve their learning outcomes and also (Patterson, Connolly, \& Ritter, 2009) who reported that students felt comfortable in class and more confident to speak since they felt teacher give them more attention personally.

\subsection{Reflection}

After the learning process, teachers had a short interviewed with some students:

Teacher: what about the second task: observe the effect of the parabola graph when the value of $b$ and $c$ were changed?

Slow learner: for the first time I look at the worksheet, I thought I couldn't solve it. It's so difficult. But my friends (fast learner) help me so much. Teach me, step by step (give some hints like my worksheet before). 
The teacher also had interviewed with fast learner:

Teacher: Did you have some difficulties in solving your first problem?

Fast learner: Yeah, a bit. But the teacher helps me when I find difficulties. I can ask for free since he checks the discussion in every group.

Teacher: how about your discussion in your second group?

Fast learner: I feel more confident with my answer in my first problem since I have to share with others. I also learn new things, observe the effect of the parabola graph when the value of a was changed.

Based on the interview, students can solve the first problem easily since the problem appropriate to their ability. Once they find some difficulties, they feel free to ask whether to friends in their group or teacher. This way is the most effective way for students to connect information and to develop their ideas to solve problems (Pham, 2011). Cooperation among students made mathematics lessons more fascinating and less stress (Awofala \& Lawani, 2020). A process of differentiating instruction enhance teachers skill as their professional development. It can be optimal if the skill is trained time by time. Not only learn the topic of differentiated instruction but use it in daily practice. Improve the strategy used and getting better performance (Dixon, Yssel, McConnell, \& Hardin, 2014). Professional development in the process of differentiated instruction potentially increases the students' achievement (Prast et al., 2018).

During the process of preparing until implementing differentiated instruction in the mathematics classroom, teachers learn to set up the best mathematics learning process, which considers various students' needs. Take into account the diversity of students' needs as the most important thing to be handled. Detail description/explanation of differentiated instruction implementation in mathematics classroom can be an insight of mathematics teachers to implement the differentiated instruction in their classroom. Further, teachers' teaching experience in a teacher professional development affects the teachers' mathematical knowledge (Ríordáin, Paolucci, \& O’ Dwyer, 2017).

\section{CONCLUSION}

This study reported that a long process in implementing differentiated instruction succeeds in making students enjoyed the learning process and achieve the learning goals through their different ways of learning. Teachers are collaborated in developing and implementing differentiated instruction in the mathematics classroom for every topic they have chosen. Steps in implementing differentiated instruction, namely pre-lesson planning, lesson planning, peer teaching, real teaching, and reflection, are the process of helping the students learn. To improve their professional development skills by implementing differentiated instruction, teachers should do it regularly in their mathematics classroom. Further, it can reveal the processes in the differentiated instruction implementation for each topic to see the details issues happening in the classroom.

\section{ACKNOWLEDGMENTS}

Thanks to all teachers for the hard work in developing differentiated instruction in the mathematics classroom for our beloved students. 


\section{REFERENCES}

Algozzine, B., \& Anderson, K. M. (2007). Tips for teaching: Differentiating instruction to include all students. Preventing School Failure: Alternative Education for Children and Youth, 51(3), 49-54. https://doi.org/10.3200/psfl.51.3.49-54

Avalos, B. (2011). Teacher professional development in teaching and teacher education over ten years. Teaching and Teacher Education, Vol. 27, pp. 10-20. Elsevier Ltd. https://doi.org/10.1016/j.tate.2010.08.007

Awofala, A. O., \& Lawani, A. O. (2020). Increasing mathematics achievement of senior secondary school students through differentiated instruction. Journal of Educational Sciences, 4(1), 1-19.

Bondie, R. S., Dahnke, C., \& Zusho, A. (2019). How does changing "one-size-fits-all" to differentiated instruction affect teaching?. Review of Research in Education, 43(1), 336362.

Borja, L. A., Soto, S. T., \& Sanchez, T. X. (2015). Differentiating instruction for EFL learners. International Journal of Humanities and Social Science, 5(81), 30-36.

Dixon, F. A., Yssel, N., McConnell, J. M., \& Hardin, T. (2014). Differentiated instruction, professional development, and teacher efficacy. Journal for the Education of the Gifted, 37(2), 111-127. https://doi.org/10.1177/0162353214529042

Fountas, I. C., \& Pinnell, G. S. (2018). Every child, every classroom, every day: From vision to action in literacy learning. The Reading Teacher, 72(1), 7-19.

Goddard, Y., Goddard, R., \& Kim, M. (2015). School instructional climate and student achievement: An examination of group norms for differentiated instruction. American Journal of Education, 122(1), 111-131. https://doi.org/10.1086/683293

Hackenberg, A. J., Creager, M., \& Eker, A. (2020). Teaching practices for differentiating mathematics instruction for middle school students. Mathematical Thinking and Learning, 1-30.

Hapsari, T., Darhim, \& Dahlan, J. A. (2018). Understanding and responding the students in learning mathematics through the differentiated instruction. Journal of Physics: Conference Series, 1013(1), 012136. https://doi.org/10.1088/1742-6596/1013/1/012136

Ismajli, H., \& Imami-Morina, I. (2018). Differentiated instruction: Understanding and applying interactive strategies to meet the needs of all the students. International Journal of Instruction, 11(3), 207-218. https://doi.org/10.12973/iji.2018.11315a

Kennedy, M. M. (2016). How does professional development improve teaching? Review of Educational Research, 86(4), 945-980. https://doi.org/10.3102/0034654315626800

Magableh, I. S. I., \& Abdullah, A. (2020). On the effectiveness of differentiated instruction in the enhancement of Jordanian students' overall achievement. International Journal of Instruction, 13(2), 533-548.

Melesse, T. (2016). Differentiated instruction: perceptions, practices and challenges of primary school teachers. Science, Technology and Arts Research Journal, 4(3), 253. https://doi.org/10.4314/star.v4i3.37

Morgan, H. (2014). Maximizing student success with differentiated learning. The Clearing House: A Journal of Educational Strategies, Issues and Ideas, 87(1), 34-38. https://doi.org/10.1080/00098655.2013.832130

Njagi, M. W. (2014). Teachers 'perspective towards differentiated instruction approach in teaching and learning of mathematics in Kenya. International Journal of Humanities and Social Science, 4(13), 236-241. 
Parsons, S. A., Dodman, S. L., \& Burrowbridge, S. C. (2013). Broadening the view of differentiated instruction: Differentiation shouldn't end with planning but should continue as teachers adapt their instruction during lessons. Phi Delta Kappan, 95(1), 38-42. https://doi.org/10.1177/003172171309500107

Patterson, J. L., Connolly, M. C., \& Ritter, S. A. (2009). Restructuring the inclusion classroom to facilitate differentiated instruction. Middle School Journal, 41(1), 46-52. https://doi.org/10.1080/00940771.2009.11461703

Pham, H. L. (2011). Differentiated instruction and the need to integrate teaching and practice. Journal of College Teaching \& Learning (TLC), 9(1), 13-20. https://doi.org/10.19030/tlc.v9i1.6710

Postholm, M. B. (2012). Teachers' professional development: A theoretical review. Educational Research, 54(4), 405-429. https://doi.org/10.1080/00131881.2012.734725

Pozas, M., Letzel, V., \& Schneider, C. (2020). Teachers and differentiated instruction: Exploring differentiation practices to address student diversity. Journal of Research in Special Educational Needs, 20(3), 217-230.

Prast, E. J., Van de Weijer-Bergsma, E., Kroesbergen, E. H., \& Van Luit, J. E. H. (2018). Differentiated instruction in primary mathematics: Effects of teacher professional development on student achievement. Learning and Instruction, 54, 22-34. https://doi.org/10.1016/j.learninstruc.2018.01.009

Ríordáin, M. N., Paolucci, C., \& O’ Dwyer, L. M. (2017). An examination of the professional development needs of out-of-field mathematics teachers. Teaching and Teacher Education, 64, 162-174. https://doi.org/10.1016/j.tate.2017.02.001

Sharp, K., Jarvis, J. M., \& McMillan, J. M. (2020). Leadership for differentiated instruction: Teachers' engagement with on-site professional learning at an Australian secondary school. International Journal of Inclusive Education, 24(8), 901-920.

Schleicher, A. (2012). Preparing teachers and developing school leaders for the 21st century. In Andreas Schleicher (Ed.), OECD Education and Skills. OECD. https://doi.org/10.1787/9789264174559-en

Scigliano, D., \& Hipsky, S. (2010). 3 ring circus of differentiated instruction. Kappa Delta Pi Record, 46(2), 82-86. https://doi.org/10.1080/00228958.2010.10516699

Sternberg, R. J., \& Zhang, L. F. (2005). Styles of thinking as a basis of differentiated instruction. Theory into practice, 44(3), 245-253. https://doi.org/10.1207/s15430421tip4403_9

Tomlinson, C. A., \& Moon, T. R. (2013). Differentiation and classroom assessment. In SAGE Handbook of Research on Classroom Assessment (pp. 414-430). United States: SAGE Publications, Inc. https://doi.org/10.4135/9781452218649.n23

Tomlinson, C. A., Moon, T., \& Imbeau, M. B. (2015). Assessment and student success in a differentiated classroom. Alexandria, VA: ASCD Professional Learning Services.

Watts-Taffe, S., Laster, B. P., Broach, L., Marinak, B., Connor, C. M. D., \& Walker-Dalhouse, D. (2012). Differentiated instruction: Making informed teacher decisions. Reading Teacher, 66(4), 303-314. https://doi.org/10.1002/TRTR.01126 